\title{
Prevalence and pregnancy outcomes in patients with antepartum haemorrhage in a tertiary hospital in Ibadan, Nigeria
}

\author{
Chinedum A. C. Onebunne*, Christopher O. Aimakhu
}

Department of Obstetrics and Gynecology, University College Hospital, Ibadan, Nigeria

Received: 27 April 2019

Accepted: 05 June 2019

\section{*Correspondence:}

Dr. Chinedum A.C. Onebunne,

E-mail: weniwediwichi@gmail.com

Copyright: () the author(s), publisher and licensee Medip Academy. This is an open-access article distributed under the terms of the Creative Commons Attribution Non-Commercial License, which permits unrestricted non-commercial use, distribution, and reproduction in any medium, provided the original work is properly cited.

\begin{abstract}
Background: Antepartum haemorrhage (APH) as one of the major obstetric emergencies contributing greatly to maternal and fetal morbidity and mortality is of serious concern in the developing world. A retrospective analysis of the APH cases and evaluation of its impact on fetal and maternal outcomes was conducted.

Methods: A retrospective study of cases managed between January 2013 and December 2014 at the University College Hospital Ibadan; all cases at a minimum of 28 weeks of gestation with antepartum bleeding were selected. Data was retrieved from the hospital records.

Results: Around 5.8\% prevalence rate of APH was documented during the study period with placental abruption and placenta praevia accounting for $46.8 \%$ and $39.2 \%$ of these cases respectively. Only $28.5 \%$ of cases were booked. Three-fifths of the women had anemia, $17.7 \%$ suffered hypovolemic shock, $33.9 \%$ also had primary PPH while 4 out of every $10(39.8 \%)$ were transfused with blood. Seven out of every ten premature deliveries (prior to 34weeks gestation) were due to placental abruption with $\mathrm{p}$ value of $<0.001$. There were 2 maternal deaths $(1 \%), 61(31 \%)$ still births and $11(5.6 \%)$ early neonatal deaths giving a perinatal mortality rate of $35.6 \%$.

Conclusions: Antepartum hemorrhage was associated with poor maternal and neonatal outcome in this study. There is need to improve on infrastructures, such as functional blood banks, appropriate antenatal care and referral system in our health facilities to be able to cope with increasing challenges of this obstetric hemorrhage.
\end{abstract}

Keywords: Antepartum haemorrhage, Abruptio Placenta, Ibadan, Maternal morbidity, Perinatal mortality, Placenta praevia

\section{INTRODUCTION}

Antepartum haemorrhage (APH) is one of the major obstetric emergencies which contribute greatly to maternal and fetal morbidity and mortality. It is defined as bleeding from or in to the genital tract prior to delivery of the baby anytime from 20 weeks gestation, in some developed countries or 24 weeks gestation, in others or 28 weeks in countries with low resource settings thus lacking adequate neonatal support facilities., ${ }^{1,2}$ APH complicates $2-5 \%$ of pregnancies. $^{3}$ The incidence deduced from a study in LAUTECH teaching hospital southwestern Nigeria was $1.5 \%$ and in Lagos University Teaching hospital, it was $3.5 \% .^{4,5}$

The causes of APH can be grouped into obstetric (bloody show, placenta praevia, abruption placenta, vasa praevia, uterine rupture, disseminated intravascular coagulation) and non-obstetric (cervicitis, cervical cancer, cervical polyps, cervical eversion, vaginitis, vaginal laceration) causes. ${ }^{6}$ Of these, APH is caused majorly by placenta praevia and abruptio placenta and occasionally some 
local causes however, the incidence of APH is much more than the combined incidence of the above causes. ${ }^{7}$ The rest cases are largely of unknown origin also called 'unexplained APH'. ${ }^{2}$ Risk factors for APH include all the risk factors for its causes for example, previous caesarean delivery, uterine structural anomaly, previous history of APH etc. APH from obstetric causes is commoner among multiparous women and those with prior history of preterm delivery. ${ }^{8} \mathrm{APH}$ is a major contributor to maternal and perinatal morbidity and mortality with several possible consequences or sequelae. Women who experience APH are generally at risk of oligohydramnios, premature rupture of membranes, preterm labour, labour induction, cesarean delivery, puerperal pyrexia, sepsis, shock, disseminated intravascular coagulation, anaemia, retained placenta, postpartum haemorrhage. Others include small for gestational age, congenital anomalies, intrauterine growth restriction, intrauterine fetal death, birth asphyxia and early neonatal death. ${ }^{9}$

The severity of bleeding in APH is varied and most often underestimated and even with proper estimation could be missing a concealed component. Based on estimates, the RCOG has classified severity of bleeding as follows: Spotting- staining, streaking or spotting noted on underwear or sanitary protection; Minor Haemorrhageblood loss less than $50 \mathrm{ml}$ that has settled; Major haemorrhage- blood loss $50-1000 \mathrm{ml}$ with no signs of clinical shock; or Massive haemorrhage- blood loss greater than $1000 \mathrm{ml}$ and/or signs of clinical shock. ${ }^{2}$

Zakia Sharafat conducted a prospective survey of pregnancies complicated by antepartum haemorrhage in Khyber Teaching Hospital, Peshawar, Pakistan over a 1 year period. The study found maternal and perinatal mortality of $2.1 \%$ and $37 \%$ respectively with anaemia (100\%), caesarean section $(68 \%)$, post-partum haemorrhage $(11.5 \%)$, need for blood transfusion $(100 \%)$, coagulation failure $(11.5 \%)$, puerperal pyrexia (13.1\%), birth asphyxia and low birth weight $(36 \%)$ as associated morbidity. ${ }^{9}$ In Melbourne, Pagano et al performed a retrospective survey of antepartum haemorrhage in The Royal Women's Hospital over a 3 year period. Their study however excluded cases of placenta praevia and reported an overall perinatal mortality of $14.5 \% .{ }^{10}$ Antepartum haemorrhage has also been studied in Nigeria. Bako et al carried out a retrospective review of cases of APH in University of Maiduguri Teaching Hospital in North-western Nigeria over an 8 year period. The study found an incidence of $1.6 \%$ with placenta praevia and placental abruption constituting $0.8 \%$ and $0.7 \%$ respectively. Predisposing risk factors were increasing maternal age, multiparity, previous abortion, previous uterine instrumentation and uterine scar. There was no maternal mortality found, the perinatal mortality was however $40.1 \% .^{11}$

In south-western Nigeria, Adekanle et al evaluated patients with antepartum haemorrhage and the pregnancy outcomes in LAUTECH teaching hospital. The study was a retrospective case control study which found the incidence of APH to be $1.5 \%$ with placenta praevia and abruption placenta responsible for $55.6 \%$ and $33.3 \%$ of cases respectively. ${ }^{4}$ About half of the patients were booked and caesarean section was required in $53.1 \%$ of deliveries. The perinatal mortality was found to be $22.2 \%$. Also in southwestern Nigeria, Obed J.Y. and Adewole I.F conducted a case control study in 374 patients of University College Hospital Ibadan evaluating the influence of first trimester bleeding on the incidence of antepartum haemorrhage. The study which revealed an incidence of $1 \%$ and $2 \%$ for abruption placenta and placenta praevia concluded that first trimester bleeding conferred a 2.5 fold increased risk of abruption placenta and placenta praevia. ${ }^{12}$

Placenta praevia is used to describe the implantation of the placenta over or very near the internal cervical os. ${ }^{13}$ It is encountered in $0.5 \%-1 \%$ of all pregnancies and is fatal in $0.03 \% .^{14}$ It is more common in multiparas, occurring 1 in 20 multiparas as against 1 in 1,500 nulliparas. ${ }^{14}$ Bleeding is more likely to occur with dilatation of the cervix. Placenta praevia is divided into 4 types or grades viz: Grade I- the placenta encroaches into the lower segment but does not reach the internal cervical os; Grade II- the placenta reaches the internal os but does not cover it; Grade III- the placenta covers the internal cervical os but not at full cervical dilatation; and Grade IV- the placenta 'sits' on the internal cervical os such that it covers it even at full cervical dilatation. ${ }^{3}$

These grades are designated " $\mathrm{A}$ " or " $\mathrm{B}$ " depending on whether the placenta is majorly on the "anterior" or "posterior" part of the uterus respectively. For the purpose of management, grade I and IIa are regarded as minor while IIb and above are major. ${ }^{3}$ It's also known as "total placenta praevia" when the placenta totally covers the os, or "partial" when the covering is partial, or "marginal" when it just gets to the edge of the internal cervical os. ${ }^{13}$ In practice, with the use of transvaginal ultrasound (cautiously), especially prior to labour, patients with the placental edge $>2 \mathrm{~cm}$ from the cervical os are considered not to have praevia. ${ }^{14}$ The use of transabdominal and transvaginal ultrasound has reduced the false-positive rate by transabdominal scanning alone, reported to be as high as $25 \%$. Also, translabial scanning is another approach, reported to be $100 \%$ sensitive for detection of a praevia. ${ }^{14}$ In Thailand, Bhutia et al reviewed in-patient medical records over a 2-month period in Siriraj Hospital to determine prevalence of placenta praevia. This was found to be $0.7 \%$ with significant outcomes of maternal blood loss $>500 \mathrm{ml}$ and Apgar score at 1 st minute of 7 or less. $60.5 \%$ of patients had normal vertex delivery. ${ }^{15}$

In southwestern Nigeria, placenta praevia cases were also reviewed by Loto et al in Obafemi Awolowo Teaching Hospitals Complex over a 10 year period. They found an incidence of $1.65 \%$ noting that $77.4 \%$ were multiparous 
and $58.2 \%$ were unbooked. ${ }^{16}$ The study revealed a perinatal mortality rate of 177 per 1000 births. In about $20 \%$ of women with placenta praevia associated with bleeding, the uterus contracts posing an additional problem of preterm labour. Other attendant effects include a longer hospital stay, caesarean delivery, placental abruption, post-partum haemorrhage, fetal malpresentation, preterm delivery, and maternal death from uterine bleeding and disseminated intravascular coagulation (DIC). ${ }^{14}$

Abruptio Placenta is premature separation of a normally sited placenta. It is a major cause of maternal morbidity and perinatal mortality globally and specially in the developing world. Abruptio placenta alone complicates about $4.5 \%$ of pregnancies in some developing countries but only one in $100-200(0.5-1 \%)$ pregnancies in the developed countries. ${ }^{17}$ In the study conducted in Lagos University Teaching Hospital Nigeria and University of Maiduguri Nigeria, its incidence was $1.3 \%$ and $0.7 \%$ respectively. Its recurrence rate is about $6 \% 3$ and after 2 abruptions the risk of recurrence increases to $25 \%$. $^{6}$ Separation of the placenta may be partial or total and the bleeding which results may be revealed (blood trickles down between the membranes through the cervix), concealed (blood collects between the placenta and the uterus without visible bleeding) or mixed (blood collects and forms haematoma while some trickle down). ${ }^{3}$ Thus, the amount of visible bleeding is a poor reflection of degree of blood loss.

The outcome in AP depends significantly on the gestational age of the fetus and the severity of the abruption. A review found that AP complicating pregnancy caused a 9-fold increase in the incidence of perinatal death, a 4-fold increase in the incidence of preterm birth and a 2-fold increase in the incidence of intrauterine growth restriction. ${ }^{6}$ In Odessa regional perinatal centre Texas, Posokhova et al, reviewed all cases of placental abruption within a 5 year period to determine associated risk factors and the maternal and fetal outcomes. They found that abruption placentae was associated with pre-eclampsia $(25.5 \%)$, diabetes $(2.6 \%)$, polyhydramnios $(8.3 \%)$, preterm premature rupture of membranes and chorioamnionitis (10.6\%), severe anaemia $(2.1 \%)$, intrauterine growth retardation and intrauterine fetal death $(13.5 \%)$ and placenta praevia $(4.6 \%) .{ }^{18}$

The combined stillbirth and first month deaths was $17.3 \%$ and there were $2(0.01 \%)$ maternal deaths. ${ }^{18}$ A 2 year retrospective study in India by Mukherjee et al also considered risk factors and maternal and fetal outcomes in patients with abruption placenta and discovered an incidence of $4.4 \%$ with nearly two-thirds of affected patients being from the low socio-economic class. Maternal mortality was $3.5 \%$ and fetal mortality was $68 \% .{ }^{17}$ In Pakistan, Sarwar et al, studied all cases of abruptio placenta over a 1 year period in Ayub Teaching, Abbottabad. Their prospective study revealed an incidence of $4.4 \%$ with intrauterine fetal demise $(58.5 \%)$, fetal distress $(36.4 \%)$ and post-partum haemorrhage $(18.9 \%)$ as the major complications. ${ }^{19}$ Caesarean section was performed in $30.2 \%$ of cases. ${ }^{19}$ In Nigeria, Igwegbe et al conducted a 10 year retrospective study in Nnamdi Azikiwe University Hospital, Nnewi, considering cases of abruptio placenta to determine the incidence, risk factors and management outcomes. They found an incidence of $0.8 \%$ with grand multiparity and age from 35 years upwards as significant risk factors. Caesarean section was conducted in $75 \%$ of cases with AP contributing $3.8 \%$ of maternal deaths within the study period. $^{20}$ The perinatal mortality rate was $52.2 \% .^{20}$ Ozumba also reviewed cases of abruptio placenta in University of Nigeria Teaching Hospital over a 3 year period and reported an incidence of $0.44 \%, 2(0.02 \%)$ maternal deaths and a perinatal mortality of $58 \% .^{21}$

Vasa praevia is the presence of foetal vessels traversing the membranes in the lower uterine segment, crossing over the cervical or below the fetal presenting part. This can occur when the cord insertion is velamentous and as such the Wharton's jelly is not present to protect the fetal vessels. ${ }^{6}$ It is rare but consequences are disastrous if not diagnosed prenatally as fetal esanguination occurs with rupture of these vessels. Vasa praevia has an incidence of approximately 1 in 5200 deliveries. ${ }^{13}$

Jain et al conducted a prospective study among patients in a teaching hospital in north India where they concentrated on the perinatal outcomes following antepartum haemorrhage. They considered the gestational age, type of antepartum haemorrhage, mode of delivery, Apgar score and birth weight as it related to the perinatal outcome. They found and overall perinatal mortality rate of $41 \%$ noting that mortality was higher in cases of abruptio placenta $(64.7 \%)$ when compared to placenta praevia or unclassified cases. ${ }^{22}$ Among the abruptio cases, mortality was more among the vaginally delivered patients $(71.4 \%){ }^{22}$

This study aimed to elucidate the outcomes with the associated morbidities which will help define the magnitude of the problem posed by antepartum haemorrhage in order to better the management measures available to promptly tackle and alleviate this problem.

\section{METHODS}

A retrospective review of cases with antepartum hemorrhage, from 28 weeks gestation, managed at the University College Hospital (UCH) Ibadan, from January 2013 to December 2014. UCH is the only Federal Government owned tertiary facility in Ibadan making it the foremost referral center in the city.

\section{Inclusion criteria}

- All pregnant women both booked and unbooked who presented to $\mathrm{UCH}$ during the study period with 
bleeding per vaginum at 28 gestational weeks or more were included in the study

- Patients were categorized according to definite diagnosis reached after history, examination and investigation results were collated.

\section{Statistical analysis}

The data was entered, cleaned and analyzed using the Statistical Package for the Social Sciences (SPSS) version 20. Frequency tables were drawn and Chi square analysis was used for categorical variables and $p$-value of $<0.5$ was considered significant.

\section{RESULTS}

There were 222 cases of APH among 3850 deliveries within the period of study which gives a prevalence of $5.8 \%$. Of these, 186 case notes and records were accessible representing $83.8 \%$ retrieval. Nearly half (46.8\%) of the women had placental abruption while $39.2 \%$ had placenta praevia (a prevalence 2.7 and $2.3 \%$ respectively).

The cause of bleeding was undetermined in $14 \%$ which included 2 women who had uterine rupture. About seventy-seven percent of the women were between 20 and 35 years of age while only $3(1.6 \%)$ teenagers were involved. About 7 out of every $10(69.8 \%)$ had a previous parous experience with 16 women $(8.6 \%)$ having at least 5 parous experiences.

Almost all the pregnancies $(97.8 \%)$ were conceived spontaneously and $95.2 \%$ were singleton pregnancies. Only $28.5 \%$ of the pregnancies were booked in UCH. Over half $(67.7 \%)$ of the women required caesarean delivery while the rest had vaginal delivery. There were 2 maternal deaths (1\%), $61(31 \%)$ still births and $11(5.6 \%)$ early neonatal deaths which amount to a perinatal mortality rate of $35.6 \%$ (Table 1 ).

Among the risk factors surveyed, $18.3 \%$ had a previous caesarean section and $10(5.4 \%)$ had a past history of APH. As much as $63.4 \%$ of the women had anaemia, 33 (17.7\%) suffered hypovolemic shock, 63 (33.9\%) also had primary $\mathrm{PPH}, 4$ out of every $10(39.8 \%)$ were transfused with at least one unit of blood, $27.4 \%$ of the fetuses were delivered before 34 weeks gestation and $21.3 \%$ required neonatal ICU support (Table 2).

Comparing outcomes/complications to the type of APH showed that $70.4 \%$ of the premature deliveries (less than 34 weeks) and $62.3 \%$ of still births were among the patients with placental abruption with $\mathrm{p}$ values $<0.001$ and 0.011 respectively. More (49.2\%) of the caesarean deliveries were due to placenta praevia and was statistically significant. Seventy $(80.4 \%)$ of the 87 patients with abruption were unbooked with p-value of 0.031 (Table 3).
Table 1: Sociodemographic characteristics and patient outcomes.

\begin{tabular}{|c|c|c|}
\hline Variable & Frequency & Present $(\%)$ \\
\hline \multicolumn{3}{|l|}{ Age (years) } \\
\hline$<20$ & 3 & 1.6 \\
\hline 20 to 34 & 143 & 76.9 \\
\hline$>35$ & 40 & 21.5 \\
\hline \multicolumn{3}{|l|}{ Marital status } \\
\hline Married & 176 & 94.6 \\
\hline Single & 10 & 5.4 \\
\hline \multicolumn{3}{|l|}{ Educational status } \\
\hline Illiterate & 38 & 20.4 \\
\hline Literate & 148 & 79.6 \\
\hline \multicolumn{3}{|l|}{ Occupation } \\
\hline Unemployed & 24 & 12.9 \\
\hline Unskilled worker & 132 & 71 \\
\hline Skilled worker & 30 & 16.1 \\
\hline \multicolumn{3}{|l|}{ Parity } \\
\hline Nullipara & 58 & 31.2 \\
\hline Para 1-4 & 112 & 60.2 \\
\hline Para $\geq 5$ & 16 & 8.6 \\
\hline \multicolumn{3}{|c|}{ Method of conception } \\
\hline Spontaneous & 182 & 97.8 \\
\hline Assisted & 4 & 2.2 \\
\hline \multicolumn{3}{|l|}{ Number of fetus } \\
\hline 1 & 177 & 95.2 \\
\hline 2 & 8 & 4.3 \\
\hline 3 & 0 & 0 \\
\hline 4 & 1 & 0.5 \\
\hline \multicolumn{3}{|l|}{ Booking in UCH } \\
\hline Booked & 53 & 28.5 \\
\hline Unbooked & 133 & 71.5 \\
\hline \multicolumn{3}{|l|}{ Antenatal anemia } \\
\hline Yes & 8 & 4.3 \\
\hline No & 106 & 57 \\
\hline Uncertain & 72 & 38.7 \\
\hline \multicolumn{3}{|c|}{ Earlypregnancy bleeding } \\
\hline Yes & 13 & 7 \\
\hline & 173 & 93 \\
\hline \multicolumn{3}{|l|}{ HTN disorder } \\
\hline Yes & 49 & 26.3 \\
\hline No & 137 & 73.7 \\
\hline \multicolumn{3}{|l|}{ History of PROM } \\
\hline Yes & 11 & 5.9 \\
\hline No & 175 & 94.1 \\
\hline \multicolumn{3}{|l|}{ Type of APH } \\
\hline Abruption & 87 & 46.8 \\
\hline Praevia & 73 & 39.2 \\
\hline Undetermined & 26 & 14 \\
\hline \multicolumn{3}{|l|}{ Mode of delivery } \\
\hline Vaginally delivery & 60 & 32.3 \\
\hline Caesarean section & 126 & 67.7 \\
\hline \multicolumn{3}{|l|}{ Maternal outcome } \\
\hline Alive & 184 & 99 \\
\hline Dead & 2 & 1 \\
\hline \multicolumn{3}{|l|}{ Fetal outcome } \\
\hline Still birth & 61 & 31 \\
\hline ENND & 11 & 5.6 \\
\hline Alive & 125 & 63.4 \\
\hline
\end{tabular}


Table 2: Associated risk factors, maternal and fetal complications.

\begin{tabular}{|lll|}
\hline Risk factors & Yes & No \\
\hline Chronic HTN $(\%)$ & $3(1.6)$ & $183(98.4)$ \\
\hline Bleeding disorders (\%) & $0(0)$ & $186(100)$ \\
\hline HTN disorder in previous pregnancy (\%) & $10(5.4)$ & $176(94.6)$ \\
\hline Previous APH (\%) & $10(5.4)$ & $176(94.6)$ \\
\hline Previous PPH (\%) & $5(2.7)$ & $181(97.3)$ \\
\hline Previous C/S (\%) & $34(18.3)$ & $152(81.7)$ \\
\hline Smoking (\%) & $1(0.5)$ & $185(99.5)$ \\
\hline Alcohol (\%) & $2(1)$ & $184(99)$ \\
\hline Maternal complications & $118(63.4)$ & $68(36.6)$ \\
\hline Anaemia (\%) & $33(17.7)$ & $153(82.3)$ \\
\hline Hypovolemic shock (\%) & $2(1)$ & $184(99)$ \\
\hline Deranged clotting time $(\%)$ & $63(33.9)$ & $123(66.1)$ \\
\hline Primary PPH (\%) & $74(39.8)$ & $112(60.2)$ \\
\hline Transfused with blood $(\%)$ & $4(2.2)$ & $182(97.8)$ \\
\hline Admitted to ICU (\%) & & \\
\hline Fetal complications & $54(27.4)$ & $143(72.6)$ \\
\hline Premature delivery $(\%)$ & $42(21.3)$ & $155(78.7)$ \\
\hline Neonatal ICU $(\%)$ & & \\
\hline
\end{tabular}

Table 3: Maternal and fetal outcomes vs APH category.

\begin{tabular}{|c|c|c|c|c|c|c|}
\hline \multicolumn{2}{|c|}{$\begin{array}{l}\text { Category outcome } \\
\text { variable }\end{array}$} & $\begin{array}{l}\text { Abruption } \\
\text { frequency }\end{array}$ & $\begin{array}{l}\text { Praevia } \\
\text { frequency }\end{array}$ & $\begin{array}{l}\text { Undetermined } \\
\text { frequency }\end{array}$ & $\begin{array}{l}\text { Total } \\
\text { frequency }\end{array}$ & $P$ value \\
\hline \multirow{2}{*}{ Booking status } & Booked (\%) & $17(32.1)$ & $28(52.8)$ & $8(15.1)$ & $53(100)$ & \multirow{2}{*}{0.031} \\
\hline & Unbooked (\%) & $70(52.6)$ & $45(33.8)$ & $18(13.5)$ & $133(100)$ & \\
\hline \multicolumn{2}{|c|}{ Hypovolemic shock (\%) } & $15(45.5)$ & $15(45.5)$ & $3(9)$ & $33(100)$ & Not sig. \\
\hline \multicolumn{2}{|c|}{ Anaemia $(\%)$} & $52(44.1)$ & $52(44.1)$ & $14(11.8)$ & $118(100)$ & Not sig. \\
\hline \multicolumn{2}{|c|}{ Deranged clotting time (\%) } & $1(50)$ & $1(50)$ & $0(0)$ & $2(100)$ & Not sig. \\
\hline \multicolumn{2}{|c|}{ Primary PPH $(\%)$} & $34(54)$ & $20(31.7)$ & $9(14.3)$ & $63(100)$ & Not sig. \\
\hline \multicolumn{2}{|c|}{ Transfused with blood (\%) } & $41(55.4)$ & $27(36.5)$ & $6(8.1)$ & $74(100)$ & Not sig. \\
\hline \multicolumn{2}{|c|}{ Admitted to ICU $(\%)$} & $1(25)$ & $2(50)$ & $1(25)$ & $4(100)$ & Not sig. \\
\hline \multicolumn{2}{|c|}{ Maternal death $(\%)$} & $1(50)$ & $1(50)$ & $0(0)$ & $2(100)$ & Not sig. \\
\hline \multirow{2}{*}{ Mode of delivery } & Vaginal (\%) & $39(65)$ & $11(18.3)$ & $10(16.7)$ & $60(100)$ & $<0.001$ \\
\hline & $\mathrm{c} / \mathrm{s}(\%)$ & $48(38.1)$ & $62(49.2)$ & $16(12.7)$ & $126(100)$ & $<0.001$ \\
\hline \multicolumn{2}{|c|}{ Premature delivery (\%) } & $38(70.4)$ & $12(22.2)$ & $4(7.4)$ & $54(100)$ & $<0.001$ \\
\hline \multicolumn{2}{|c|}{ Neonatal ICU (\%) } & $22(52.4)$ & $12(28.6)$ & $8(19)$ & $42(100)$ & Not sig. \\
\hline \multicolumn{2}{|l|}{ Still birth (\%) } & $38(62.3)$ & $16(26.2)$ & $7(11.5)$ & $61(100)$ & 0.011 \\
\hline \multicolumn{2}{|c|}{ Early neonatal death (\%) } & $8(72.7)$ & $1(9.1)$ & $2(18.2)$ & $11(100)$ & Not sig. \\
\hline
\end{tabular}

\section{DISCUSSION}

The prevalence of antepartum hemorrhage was $5.8 \%$ which is almost the same as found by Zakia Sharafat who reported a value of $3.07 \%$ but slightly higher than the incidence of $1.5 \%$ and $1.6 \%$ reported by Adekunle et al and Bako et al respectively. ${ }^{4,9,11}$ The prevalence of abruption placenta was $2.7 \%$ which is similar to the $4.4 \%$ reported by Sawar et al and Mukherjee et al but higher than the $0.8 \%, 1 \%$ and $0.44 \%$ incidences reported by Igwegbe et al, Obed et al and Ozumbar respectively, ${ }^{12,19-}$ 21 Placenta praevia had a prevalence of $2.3 \%$ which compared with $2 \%$ found by Obed et al and $1.65 \%$ found by Loto et al but is higher than the $0.7 \%$ reported by Bhutia et al. ${ }^{12,15,16}$. Majority $(71.5 \%)$ of the pregnancies were unbooked which agrees with the study by Mukherjee et al and Zakia, however Siamalambwa et al reported only $1.4 \% \%$ as unbooked cases who did not attend antenatal clinic., ${ }^{9,17,23}$ The relatively high percentage of unbooked cases may be explained by the fact that the Hospital of study is the major referral center in the city. This could also explain the high incidences. Over four-fifths of the abruption cases were among the unbooked patients while just about three-fifths of the previa cases were unbooked and this difference was statistically significant. Anemia was a major morbidity 
affecting $63.4 \%$ however this is much less than the $96 \%$ reported by Mukherjee et al or the $100 \%$ reported by Zakia. This may be explained by the varied timing of bleeding especially with placenta praevia. Patients who experienced vaginal bleeding while on admission may receive prompt attention that may avert anemia. Also, $57 \%$ of the patients did not have anemia prior to bleeding and as such may still have normal hematocrit values in the event of mild bleeding episodes. Up to $33.9 \%$ experienced primary post-partum hemorrhage (PPH) and $39.8 \%$ of the women had bleeding severe enough to warrant blood transfusion. These differ from the figures found by Zakia where $11.5 \%$ who had PPH and all the patients received blood transfusion. These values may also be explained by the prior (antenatal) hematocrit values which were normal in $57 \%$. More of the patients with PPH had placental abruption first though this difference was not statistically significant. The caesarean section rate was very high at $67.7 \%$, however, this compares to the $68.4 \%, 63.7 \%$ and reported by Zakia, Bako et al and Siamalambwa respectively., ${ }^{9,11,23}$ The maternal mortality was high at $1 \%$ when compared to no deaths reported by Siamalambwa et al and Bako et al. Zakia however reported a maternal mortality of $2.1 \%$. Over a quarter of the deliveries were prior to 34 weeks gestation (at which stage lung maturity is expected) and $21.3 \%$ required admission for neonatal ICU support. This is similar to the $26 \%$ delivery rate prior to 34 weeks gestation found by Zakia, however as much as $42 \%$ required admission into the nursery. ${ }^{9}$ More than three fifths of the premature deliveries were due to abruptio placenta and this was statistically significant. The perinatal mortality rate was very high at $35.6 \%$ which is similar to $37 \%, 40.1 \%$ and $41 \%$ rates reported by Zakia, Bako et al and Jain et al respectively. ${ }^{9,11,22}$ Relatively lower rates of $22.2 \%$ and $14.5 \%$ were reported by Adekanle et al and Pagano et al respectively. ${ }^{4,10}$ Most of the perinatal mortalities were in the form of still births and over three-fifths of the still births were due to placental abruptio which was statistically significant. Early diagnosis and intervention for placental abruption cases will help prevent these still births. Antepartum hemorrhage was found to be associated with poor maternal and neonatal outcome in this study and majority not booked for antenatal care. There is need to improve on infrastructures, such as functional blood banks, quality of care and referral system in our health facilities as well as implant measures to ensure antenatal care for all to better cope with challenges of this obstetric hemorrhage.

\section{ACKNOWLEDGMENTS}

Dr. Ezinne Onebunne was immensely instrumental during the discouraging periods of retrieving data and insisted this work be shared with others.

Funding: No funding sources Conflict of interest: None declared Ethical approval: Not required

\section{REFERENCES}

1. Giordano R, Cacciatore A, Cignini P, Vigna R, Romano M. Antepartum haemorrhage. J Prenat Med. 2010; 4(1):12-6.

2. Royal College of Obstetricians and Gynaecologists. Antepartum Haemorrhage. Green top guidelines. 2011.

3. Aimakhu $\mathrm{CO}$, Iwe $\mathrm{CAB}$, Umoh A. Antepartum Haemorrhage. Ibom Med J. 2006;1(1).

4. Adekanle D, Adeyemi A, Fadero F. Antepartum haemorrhage and pregnancy outcome in LAUTECH teaching Hospital Southwestern Nigeria. J Med Med Sci. 2011;2(12):1243-7.

5. Adegbola R, Okunowo A. Pattern of Antepartum Haemorrhage at the Lagos University Teaching Hospital, Lagos, Nigeria. Niger Med Pract. SAME Ventures. 2010;56(1-2).

6. DeCherney A, Neri L, Lauren N, Roman A. Current Diagnosis and Treatment Obstetrics and Gynecology. 11th ed. The McGraw-Hill Companies. 2013;1657.

7. Pitkin J, Peattie AB, Magowan BA. Obstetrics and Gynaecology, An Illustrated Colour Text. Churchill Livingstone. 2003:172.

8. Pernoll ML. Benson and Pernoll's Handbook of Obstetrics and Gynaecology. 10th ed. McGraw-Hill; 2001:931.

9. Zakia S. A Survey of pregnancies complicated by antepartum haemorrhage. Med Forum Mon. 2014;25(7).

10. Pagano R, Adey FD, Butterfield LJ. The management of antepartum haemorrhage (excluding placenta praevia). Aust N Z J Obstet Gynaecol. 1983;23(1):20-4.

11. Bako B, Audu B, Chama C, Kyari O, Idrissa A. An 8 year clinical review of antepartum haemorrhage at the University of Maiduguri Teaching Hospital, Maiduguri. Borno Med J. 2013;5(2).

12. Obed JY, Adewole IF. Antepartum haemorrhage: the influence of first trimester uterine bleeding. West Afr J Med. 1997;15(1):61-3.

13. Cunningham FG, Leveno KJ. editors. Williams Obstetrics. 23 ${ }^{\text {rd }}$ ed. McGrawHill; 2010:1404.

14. Gibbs R., Karlan B., Haney A., Nygaard I., editors. Danforth's Obstetrics and Gynecology. $10^{\text {th }}$ ed. Lippincott Williams and Wilkins: 2008.

15. Bhutia PC, Lertbunnaphong T, Wongwananuruk T, Boriboonhirunsarn D. Prevalence of pregnancy with placenta previa in Siriraj Hospital. Siriraj Med J. 2011;63(6):191-5.

16. Loto O, Onile TG. Placenta praevia at the Obafemi Awolowo University Teaching Hospitals Complex, Ile-Ife. A ten year analysis. Niger J Clin Pract. 2008;11(2):130-3.

17. Mukherjee S, Bawa AK, Sharma S, Nandanwar YS, Gadam M. Retrospective study of risk factors and maternal and fetal outcome in patients with abruptio placentae. J Nat Sci Biol Med. 2014;5(2):425-8.

18. Posokhova SP, Ryazancev I, Mazur P. Risk factors 
predisposing to abruptio placentae. Maternal and fetal outcome. Int J Gynecol Obstet. 2012;119:S736.

19. Sarwar I, Abbasi A un N, Islam A. Abruptio placentae and its complications at Ayub Teaching Hospital Abbottabad. J Ayub Med Coll Abbottabad. 2006;18(1):27-31.

20. Igwegbe AO, Eleje GU, Okpala BC. Management outcomes of abruptio placentae at Nnamdi Azikiwe University Teaching Hospital, Nnewi, Nigeria. Niger J Med. 2013;22(3):234-8.

21. Ozumba BC. Abruptio placentae at the University of Nigeria Teaching Hospital, Enugu: a 3-year study. Aust N Z J Obstet Gynaecol. 1989;29(2):117-20.

22. Jain S, Jain N, Dahiya P, Rohilla S, Malik R. Perinatal outcome in antepartum hemorrhage in teaching hospital of northern India-A prospective study. Int J Sci Res Publ. 2015;5(1):2250-3153.

23. Siamalambwa Q. Patient Characteristics and Outcomes In Antepartum Haemorrhage due to Placenta Praevia and Abruptio Placenta at the University Teaching Hospital, Lusaka, Zambia. University of Zambia; 2015.

Cite this article as: Onebunne CAC, Aimakhu C. Prevalence and pregnancy outcomes in patients with antepartum haemorrhage in a Tertiary Hospital in Ibadan. Int J Reprod Contracept Obstet Gynecol 2019;8:2631-7. 